\title{
Japan ponders steps to probe data errors
}

David Cyranoski, Tokyo

Where does the border lie between simple error and scientific misconduct? That is the question thrust in the face of the Japanese research community by the unsavoury means of an anonymous letter.

The letter was sent to funding agencies and publishers throughout Japan, Europe and the United States in August 2001. It concerned papers by Takuji Tanaka, a cancer researcher at Kanazawa Medical University. The anonymous author claimed that there were some unusual similarities between figures in an article on foods that may help to prevent cancer published in September 1997 in the Japanese Journal of Cancer Research ( $\mathrm{T}$. Tanaka et al. Jpn J. Cancer Res. 88, 821-830; 1997) and those in a 1999 paper in Carcinogenesis (T. Tanaka et al. Carcinogenesis 20, 1477-1484; 1999). The letter says that both papers include two identical figures for polyamine compounds in rats, even though the two experiments used different numbers of rats for different lengths of time. The letter went on to allege that this was just one of at least 30 discrepancies in articles by Tanaka.

In January 2002, the Japanese Journal of Cancer Research ran a correction to the 1997 paper (Jpn J. Cancer Res. 93, 109; 2002). "It was a clear mistake," admits Tanaka, "but I have never fabricated data." He also denies any misconduct in the other cases.

Tanaka's supporters say that he is the target of an unjustified personal attack, and they reject the anonymous author's claim that he or she is acting on behalf of an unnamed watchdog group dedicated to protecting scientific integrity. The author's allegations are limited to Tanaka. "He or she just wants Tanaka to lose his job," says Hideki Mori, head of the medical department at Gifu University and a co-author on the two papers mentioned in the letter. "Tanaka's reputation has suffered unfairly."

Mori suggests that Tanaka should take the case to a lawyer or the police. "The author of the letter is like a stalker," notes Mori, who claims to have a very good idea of the author's identity.

But it would be healthy for the scientific community to have a mechanism in place to investigate such charges properly, Mori points out. Japan lacks anything like the US health department's Office of Research Integrity, and officials at both the ministry of education and ministry of health say that there is no system in place to look at cases of misconduct.

Masaaki Terada, editor of the Japanese Journal of Cancer Research and a former director of the National Cancer Center in Tokyo, says that he did wonder whether the allegations should be raised with anyone other than his journal's executive editors. He agrees that Japan needs a system to investigate misconduct accusations, and says that he plans to raise the question with the health ministry. "There should be a government- level body to deal with this," says Terada.

The problem of misconduct is especially difficult in Japan because the society does not look kindly on insiders who blow the whistle, says Tokai University's Kiyoshi Kurokawa. "Even if you want to report a problem to your professor, he may be afraid of his dean or hospital director, who will be afraid of the education ministry," says Kurokawa. "Such reporting may backfire."

Some critics say that the reluctance to criticize others, especially those in established positions, was to blame for one of Japan's most notorious misconduct case - the 25 years of research in which an archaeologist pushed back Japan's stone age some 600,000 years with his 'discoveries' of planted relics. After the fraud came to light, many researchers claimed that they had doubted the findings all along.

More broadly, a spate of scandals in industry and government circles has brought the problem of encouraging and protecting whistleblowers to centre stage. The cabinet office is currently considering a system to protect informants.

Kurokawa, who is vice-president of the Science Council of Japan, an organization that represents thousands of scientists, has established a committee to come up with guidelines on the subject of scientific misconduct. Such a system could also offer protection from false accusations, Mori points out. Additional reporting by Oliver Schmidt.

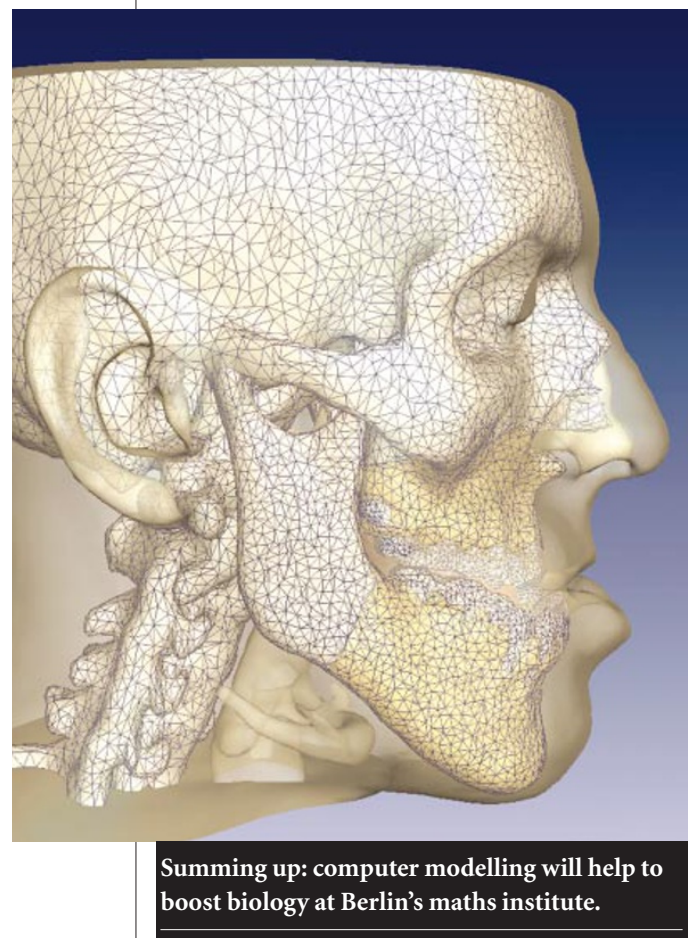

\section{Maths adds up for Berlin centre}

Quirin Schiermeier, Munich

A centre that will apply mathematics to problems in physics, biology, telecommunications and transportation has opened its doors in Berlin. Advocates say that it could catapult the German capital to the top of the league in mathematics research.

Over the next four years, the DFG Research Centre for Mathematics for Key Technologies will receive 5 million euros (US\$5 million) per year from the DFG, Germany's main research funding agency, and a further 3 million euros per year from Berlin's state government.

"This is big money for mathematics," says Martin Grötschel, vice-president of the Konrad Zuse Centre for Information Technology in Berlin and spokesman for the new centre.

"The nature of our discipline allows us to invest the bulk of the money in people, rather than in equipment," says Grötschel. Six new full professors, seven young principal investigators and 60 other scientific staff will be hired at the centre in the coming months.

Günter Ziegler, a mathematician at the Technical University of Berlin, who last year won the DFG's prestigious Leibniz prize, is enthusiastic about the new investment. He says that the funding boost should help to block the brain drain of mathematicians from German academic positions to industry and to the United States, where mathematics is winning increased support from the National Science Foundation (see Nature 414, 676; 2001).

Any concern that the new DFG research centre's emphasis on applications will be at odds with fundamental research is groundless, says Grötschel. "Modelling common problems in industry, banking and science will require new algorithms," he says. "This will trigger a loop of research that is equally beneficial" to both theoretical and practical mathematics. 